\title{
O DIREITO À BUSCA DA FELICIDADE: A SUA POSSÍVEL APLICAÇÃ̃ COMO UM DIREITO FUNDAMENTAL NO BRASIL ${ }^{1}$
}

THE RIGHT TO SEARCH FOR HAPPINESS: ITS POSSIBLE APPLICATION AS A FUNDAMENTAL RIGHT IN BRAZIL

Giulia SCARPELLINI²

Cildo GIOLO JÚNIOR

ISSUE DOI: 10.21207/2675-0104.2019.899

\section{RESUMO}

O objetivo geral do presente artigo é investigar se a busca da felicidade pode ser caracterizada como um direito fundamental no ordenamento jurídico brasileiro. Para isso, reflete-se o conceito de felicidade, tanto no âmbito da Filosofia, quanto no da Ciência, permeando, ainda, os ordenamentos jurídicos estrangeiros, a fim de encontrar uma conclusão sobre a situação da felicidade no direito comparado. Faz-se, ainda, uma análise dos direitos fundamentais, dos direitos humanos e da dignidade da pessoa humana, com o propósito de melhor entendimento do tema. Por fim, explora-se a felicidade

\footnotetext{
${ }^{1} \mathrm{O}$ presente artigo sintetiza a monografia de conclusão da pesquisa, realizada para o Programa Interno de Bolsas de Iniciação Científica (PIBIC 2018-2019) da Faculdade de Direito de Franca (FDF), Franca/SP.

${ }^{2}$ Discente da Faculdade de Direito de Franca (FDF), Franca/SP. Bolsista do Programa Interno de Bolsas de Iniciação Científica (PIBIC 2018-2019).

${ }^{3}$ Pós-Doutor em Direitos Humanos pelo "Ius Gentium Conimbrigae" (IGC/CDH) da Faculdade de Direito da Universidade de Coimbra (UC), Portugal. Doutor em Direito pela Universidade Metropolitana de Santos (UNIMES). Doutor em Ciências Jurídicas e Sociais pela UMSA (Buenos Aires - Argentina). Mestre em Direito Público pela Universidade de Franca (UNIFRAN), Franca/SP. Especialista em Direito Processual Civil na Faculdade de Direito de Franca (FDF), Franca/SP. Graduado em Direito pela Faculdade de Direito de Franca (FDF), Franca/SP. Professor Titular da cadeira de Direito Civil na Faculdade de Direito de Franca (FDF), Franca/SP.
} 
no contexto do direito brasileiro e conclui-se que não é possível caracterizar a busca da felicidade como um direito fundamental, em razão da difícil conceituação do bem-estar subjetivo.

Palavras-chave: Felicidade. Direitos fundamentais. Direito à busca da felicidade.

\begin{abstract}
The main goal of this article is to inquire if the pursuit of happiness can be characterized as a fundamental right in the Brazilian legal order. For this, the definition of happiness reflects on the context of Philosophy as on the Science context, permeating the foreign legal order, in order to find a conclusion about the happiness situation on the comparative law. It is also made an analysis of the fundamental rights, human rights and a human dignity for a better understanding about the subject. Eventually, it is explored happiness on the Brazilian law contexto and it is concluded that it's not possible to characterize the pursuit of happiness as a fundamental right due to the hard conception of the subjective well-being.
\end{abstract}

Keywords: Happiness. Fundamental Rights. The Right of Pursuit for Happiness. 1

1

\title{
INTRODUÇÃO
}

A felicidade comumente integra as preocupações e reflexões dos seres humanos, desde os primórdios da humanidade. Apesar de, na atualidade, parecer figurar-se como tema somente da literatura conhecida como "autoajuda", a felicidade vem sendo estudada pela Filosofia, assim como pela Ciência, há muito tempo. Dessa forma, para essas áreas, "o que é felicidade?" ou "o que fazer para aumentar a felicidade?" são consideradas algumas das indagações essenciais.

Entretanto, juridicamente, a sua introdução como objeto de estudo é inovadora e sem precedentes no Brasil. Desse modo, ela encontrase em uma situação indefinida, apesar de já ter servido de fundamento em algumas das mais notórias decisões do Supremo Tribunal Federal.

À vista disso, o objetivo principal do presente artigo é investigar a possiblidade da busca da felicidade ser considerada um direito fundamental e de ser aplicada no Brasil. Para isso, analisa-se, suscintamente, a felicidade sob os âmbitos da Filosofia e da Ciência, além de realizar-se o exame de documentos jurídicos estrangeiros. Ainda, necessária é a compreensão acerca dos direitos fundamentais, portanto, fazse a conceituação e verificação histórica dos direitos fundamentais, assim como a distinção desses dos direitos humanos. Explora-se, também, a dignidade da pessoa humana, em razão do vínculo dessa com a felicidade. Por fim, investiga-se o direito à busca da felicidade no ordenamento jurídico brasileiro, com a apuração de jurisprudências e da PEC da Felicidade. 
Para essa pesquisa, procedeu-se a um levantamento bibliográfico centrado no Direito Constitucional, nos Direitos Humanos e no Direito Comparado, acompanhado por um estudo interdisciplinar estabelecido entre a Filosofia, a Psicologia, a Economia, as Ciências Sociais, entre outros.

\section{A FELICIDADE}

Para um melhor discernimento da expressão "felicidade", essa análise foi dividida em 3 partes: uma sob o âmbito da Filosofia; outra sob a visão da Ciência; e, por último, uma comparação do assunto entre documentos jurídicos de diversos países.

\subsection{FELICIDADE NA FILOSOFIA}

Primeiramente, a respeito da etimologia, a palavra "felicidade" frequentemente é relacionada a sorte. Nesse sentido, o filósofo, sociólogo e historiador das religiões Fréderic Lenoir dispõe:

as diversas etimologias da palavra remetem quase sempre à noção de sorte, de destino favorável. Em grego, eudaimonia pode ser entendida como ter um bom daimôn. Hoje diríamos: ter um anjo guardião, ou ter nascido sob uma boa estrela. Em francês, bonheur vem do latim bonum angurium: "bom augúrio" ou "boa fortuna". Em inglês, happiness provém da raiz islandesa happ, "sorte". (LENOIR, 2016)

Sócrates elevou a eudaimonia - felicidade - a um bem soberano na filosofia. Para ele A principal questão passou a ser: qual o significado de vida boa. Essa vida boa englobaria a felicidade e a virtude.

Conhecido como o "pai do livre-arbítrio", Aristóteles tem uma vasta obra em que a felicidade permeia os estudos, sendo "Ética à Nicômaco" a mais importante. Aristóteles alegava que a felicidade (eudaimonia) dependia, especialmente, da sorte, entretanto, com bons comportamentos - as chamadas virtudes - poderia ser aumentada. Para ele, a felicidade é a finalidade última do homem. Ainda, reconhecia a importância dos prazeres, dos bens materiais e da honra para o alcance da felicidade, sendo eles considerados como um meio. 
Outro filósofo grego, Epicuro, apresentou uma fórmula para a felicidade: um estilo de vida simples, ser gentil com os outros e rodear-se de amigos. Se a vida do indivíduo for simples, os seus desejos também o serão, e, portanto, facilmente satisfeitos. Epicuro, ademais, enxergava a necessidade de ser moderado.

Kant compreendia a felicidade de forma distinta dos outros filósofos. Para ele, ela seria somente a satisfação dos desejos humanos, não importando quais eles fossem. Ainda, não diferenciava os prazeres em superiores e inferiores; todos estavam no mesmo patamar e poderiam produzir a mesma quantidade de felicidade.

Jeremy Bentham foi um filósofo inglês que deu grande importância à felicidade. Criou o utilitarismo ou o princípio da maior felicidade, uma teoria sobre como deve-se viver. Dessa forma, a conduta mais correta seria aquela que trouxesse maior felicidade ao indivíduo. Para Bentham, felicidade significava prazer e ausência de dor. Acreditava na medição do prazer e na comparação de diferentes prazeres, em uma mesma escala e unidades. Assim, inventou o cálculo felicífico para quantificar a felicidade. Ainda, entendia que os animais também podiam experimentar a felicidade, uma vez que esta não estava relacionada à racionalidade. Entretanto, sua teoria foi considerada radical e rechaçada por muitos estudiosos.

Um dos principais críticos do utilitarismo de Jeremy Bentham foi o seu próprio pupilo, John Stuart Mill. Este retomou a teoria, dando novo enfoque. Concordava com a ideia de que a conduta mais acertada seria aquela que produzisse maior felicidade, entretanto, discordava da equiparação entre felicidade e prazer. Mill acreditava em diferentes tipos de prazeres, distinguindo-os em uns mais elevados e outros menos. Para ele, alguns prazeres são melhores que outros. Os inferiores seriam aqueles que qualquer animal poderia vivenciar, enquanto os superiores, somente os seres humanos alcançariam - e envolveriam, frequentemente, o uso do intelecto.

Diante de todo o exposto, finaliza-se a suscinta investigação acerca da felicidade pelo âmbito da Filosofia, concluindo-se que a felicidade comumente era tema das indagações dos filósofos e estes a conceituavam, muitas vezes, de formas díspares.

\subsection{FELICIDADE NA CIÊNCIA}


Do mesmo modo que na filosofia, na área científica a felicidade é amplamente discutida e explorada, sendo correlacionada com os mais variados temas. Após a investigação do assunto em diversos artigos científicos das esferas médica, psicológica e, inclusive, socioeconômica, pôde-se observar que a expressão "felicidade" ganhou notoriedade dentro da Ciência após a Segunda Guerra Mundial, particularmente nas décadas de 1960 e 1970. Nestas áreas, é comum denominar a felicidade de bemestar subjetivo e, os determinantes necessários para o alcance desse estado (como renda, saúde, relações interpessoais, entre outros), de bem-estar objetivo.

Entre todas as determinantes estudadas, aquelas que influenciam o bem-estar subjetivo de forma individual, são: desemprego, idade, relações interpessoais, fé, características pessoais, tais como a resiliência e a extroversão, e ausência de doenças. Em relação à questão econômica não foi possível chegar a resultados conclusivos.

No tocante à esfera coletiva, em contraste com o PIB (Produto Interno Bruto) e com o objetivo de determinar a felicidade da população de um país, foi criado pelo Reino do Butão, em 1972, o indicador sistêmico Felicidade Interna Bruta (FIB). A partir de então, incentivados pelo Programa das Nações Unidas para o Desenvolvimento (PNUD), outros países introduziram este conceito na medição do próprio progresso. Assim, para a estimativa do FIB, além de analisar o total dos valores contabilizados a partir da produção de bens e serviços, outros aspectos devem ser ponderados, tais como educação, cultura, bem-estar psicológico, saúde, uso do tempo, meio ambiente, entre outros.

Dito isso, e com base no Relatório Mundial da Felicidade ${ }^{4}$, conclui-se que a felicidade de um país não está diretamente relacionada à

\footnotetext{
${ }^{4}$ Em inglês, World Happiness Report. Após o Reino do Butão adotar o FIB como o principal indicador de desenvolvimento, a Assembleia da ONU, em 2011, passou a incentivar os países membros a medir a felicidade de sua população e utilizar os dados para fomentar políticas públicas. Em 2012, houve a primeira Reunião de Alto Nível da ONU sobre a "Felicidade e Bem-Estar: Definindo um Novo Paradigma Econômico". O primeiro Relatório Mundial da Felicidade foi difundido em 1 de abril de 2012, sendo celebrada como a primeira pesquisa sobre felicidade global. O segundo foi lançado em 2013, sendo uma complementação do primeiro. Para os anos seguintes, foram emitidas publicações anuais. Os dados são coletados de pessoas em mais de 150 países. A escala é de 0 a 10 , a qual é monitorada com o passar do tempo e comparada com a de outros países. Atualmente, essas variáveis incluem: PIB per capita real, assistência social, expectativa de vida saudável, liberdade para fazer escolhas, generosidade e percepções de corrupção. Cada país também é comparado a um país hipotético chamado Distopia. Distopia representa as menores médias nacionais para cada variável chave e, juntamente com erros residuais, é usado como ponto de referência de regressão. Disponível em: <https://pt.wikipedia.org/wiki/Relat\%C3\%B3rio_Mundial_da_Felicidade>. Acesso em: 11/12/2018.
} 
riqueza monetária. No Ranking of Happiness de 2015-2017, o país considerado mais feliz foi a Finlândia, a qual se encontra na posição de $119^{\circ}$ do ranking econômico mundial de 2017. Em contrapartida, países intitulados "ricos", como os Estados Unidos e a China, estão posicionados em $18^{\circ}$ e $86^{\circ}$. O Brasil encontra-se na $28^{a}$ posição do ranking da felicidade, enquanto é a $8^{\mathrm{a}}$ economia do mundo.

Em conclusão, no presente estudo, foi possível constatar que a Ciência tem como enfoque examinar as causas da felicidade, tanto na esfera individual como na coletiva. Dessa forma, a felicidade "é um fenômeno predominantemente subjetivo, mais subordinado a traços psicológicos, socioculturais e até genéticos, do que estritamente a fatores ou eventos isolados e externamente determinados" (SEABRA, 2018).

\subsection{FELICIDADE NO DIREITO COMPARADO}

A felicidade, por ser um dos principais anseios humanos, em várias Constituições e Declarações de diferentes nações são encontradas referências expressas a ela. A primeira aparição do termo "felicidade" em um texto jurídico e político foi nos Estados Unidos da América, na Declaração de Direitos da Virgínia, em 1776. Dispunha que a busca pela felicidade era um dos direitos naturais do ser humano e um dos objetivos centrais do governo, sendo que este deveria ser capaz de produzir a maior felicidade ao seu povo.

Ainda em 1776 nos Estados Unidos, a Declaração de Independência do país, idealizada por Thomas Jefferson, também incluiu a felicidade em sua redação, fazendo-se quase uma cópia do conteúdo da Declaração de Direitos da Virgínia. Posteriormente à Declaração de Independência, várias constituições estaduais estado-unidenses passaram a incluir o termo felicidade em seus escritos. Nas análises de jurisprudências realizadas por Tourinho Leal, foi possível notar que a expressão "felicidade" é amplamente empregada como fundamento, entretanto apresenta diversas conceituações.

Outro documento memorável e de grande importância que citou a felicidade em seu texto é a Declaração de Direitos do Homem e do Cidadão, de 1789, a qual culminou da Revolução Francesa. Seguindo os ideais iluministas da época, o termo "felicidade" foi inserido no preâmbulo da Declaração de Direitos da França, evidenciando-se a noção da felicidade 
coletiva - ou seja, as reivindicações dos cidadãos devem sempre estar voltadas à felicidade geral - e a revelando como um objetivo a ser perseguido tanto pela população, quanto pelos Poderes Legislativos e Executivos. A atual Constituição Francesa, promulgada em 1958, em seu preâmbulo, mantém o compromisso com direitos humanos proclamados na Declaração de 1789. Dessa forma, a ideia coletiva de felicidade ainda permanece no ramo jurídico francês, apesar de não expressamente redigido.

Outro país que inseriu em sua Carta Constitucional a noção de felicidade foi o Japão, promulgando-a em 1946 e que vigora até os dias atuais. Nesse sentido, a Constituição Japonesa iguala a busca pela felicidade à vida e à liberdade, considerando-as direitos que devem ser apreciados pela Legislação e pelo Governo, respeitando-se o bem-estar público. Essa concepção assemelha-se à estado-unidense, o que pode ter como fundamento a histórica intervenção e consequente influência dos Estados Unidos no Japão após a Segunda Guerra Mundial.

Influenciada pela Constituição Japonesa, a Coréia do Sul, em 1948, também inseriu menções à felicidade em sua Constituição Federal. Em seu art. 10 revela que todos os cidadãos têm o direito à busca pela felicidade. Na jurisprudência sul coreana, segundo os estudos de Tourinho Leal, é amplamente utilizada como fundamento e geralmente se relaciona com a liberdade e a autodecisão. Entretanto, no país, existem muitas críticas à presença desse direito na Constituição e à ampla utilização dele em julgados do Tribunal.

Por fim, outro país asiático que abarcou a felicidade em documentos jurídicos foi o Butão. Este, aliás, foi além. Criou o índice Felicidade Interna Bruta (FIB), o qual mensura a satisfação da população com base nos serviços e condições de vida que o Estado fornece, conforme já citado anteriormente. Ademais, A Constituição do Butão, pequeno país encravado nas montanhas do Himalaia, mencionou expressamente a felicidade. Assim, no Butão, a felicidade deve ser assegurada, reforçada e proporcionada pelo Estado, o qual deve esforçar-se para promover as condições que possibilitem alcançar a "Felicidade Nacional Bruta" (Gross National Happiness) (LEAL, 2017).

Em suma, é possível observar que a expressão "felicidade" foi abrangida em alguns textos jurídicos ao redor do mundo. Ainda, ela é geralmente relacionada a uma garantia do indivíduo e a uma função do Estado. 


\section{OS DIREITOS FUNDAMENTAIS, OS DIREITOS HUMANOS E A DIGNIDADE DA PESSOA HUMANA}

Há autores que defendem que os direitos fundamentais são tão antigos quanto as próprias civilizações, podendo ser vistos vestígios no direito da Babilônia, por volta do ano 2000 a.c., na Grécia Antiga e suas pólis, na Roma Republicana e, ainda, na Idade Média dominada pela teologia cristã. Entretanto, não existem estudos suficientes para a confirmação.

Dito isso, a Magna Carta da Inglaterra de 1215 é considerada a primeira manifestação dos direitos fundamentais no direito positivo. Após esse episódio, apesar de diversas outras legislações terem sido publicadas, foram a Declaração de Direitos do Povo da Virgínia, de 1776, dos Estados Unidos da América e a Declaração dos Direitos do Homem e do Cidadão, de 1789, da França que instituíram os direitos fundamentais como são conhecidos atualmente.

Diante do exposto, a fim de se estudar os direitos fundamentais e sua evolução, foi criado, de forma didática, as chamadas "gerações/dimensões". Nesse sentido, a primeira dimensão dos direitos fundamentais é caracterizada pelo pensamento liberal-burguês do século XVIII, de feição individualista, reflexo das primeiras constituições positivadas. São direitos projetados como defesa do indivíduo perante o Estado. Em função disso, são identificados como "negativos", ou seja, requerem uma abstenção do Estado e não uma conduta ativa. São exemplos o direito à liberdade, à vida, à propriedade e à igualdade.

A Revolução Industrial ocorrida no século XIX e seus efeitos miseráveis para a população trabalhadora geraram movimentos reivindicatórios de direitos trabalhistas, de assistência social, segurança, saúde e educação. Dessa forma, a segunda dimensão dos direitos fundamentais é de cunho "positivo", uma vez que pretende ações positivas por parte do poder público.

A terceira dimensão, influenciada pelas atrocidades e decorrências da Segunda Guerra Mundial, bem como pelas diversas intervenções humanas na natureza, engloba os, usualmente, chamados direitos de fraternidade ou solidariedade. Entre eles estão os direitos à paz, à autodeterminação dos povos, ao desenvolvimento, ao meio ambiente $\mathrm{e}$ qualidade de vida. 
Ademais, há autores que defendem a existência da quarta, da quinta e, até, da sexta dimensão. A quarta dimensão seria caracterizada pelos resultados da globalização, sendo composta pelo direito à democracia e à informação. A suposta quinta dimensão dos direitos fundamentais estaria relacionada às consequências da Internet e da realidade virtual, tal como às dificuldades da sociedade tecnológica. Já a sexta dimensão, estaria vinculada ao direito dos seres humanos ao acesso à água potável.

Em relação ao conceito dos direitos fundamentais, os autores Dimitri Dimoulis e Leonardo Martins afirmam que "são direitos públicosubjetivos de pessoas (físicas ou jurídicas), contidos em dispositivos constitucionais e, portanto, que encerram caráter normativo supremo dentro do Estado, tendo como finalidade limitar o exercício do poder estatal em face da liberdade individual” (DIMOULIS e MARTINS, 2014).

A respeito dos direitos humanos, para o filósofo e jurista argentino Carlos Santiago Niño "a expressão direitos humanos representa, em sentido amplo, o conjunto das atividades realizadas de maneira consciente, com o objetivo de assegurar ao homem a dignidade e evitar que passe por sofrimentos" (CASTILHO, 2012). Entretanto, para a maioria dos estudiosos, é impossível enquadrar o significado de direitos humanos em uma única frase.

Vários juristas e doutrinadores apontam que há uma diferença entre direitos fundamentais e humanos, a qual foi primeiramente apresentada pela doutrina alemã: os direitos humanos seriam aqueles naturais aos homens, demonstrando uma concepção jusnaturalista, enquanto os direitos fundamentais seriam os direitos humanos reconhecidos e positivados nas Constituições dos países, manifestando, assim, uma concepção positivista.

O mais afamado e importante marco contemporâneo para os direitos humanos foi a Declaração Universal de Direitos Humanos, aprovada pela Organização das Nações Unidas (ONU) em 1948 e elaborada com base nos eventos da Segunda Guerra Mundial, a fim de evitar que outros como estes viessem a ocorrer. A referida Declaração trouxe universalidade e indivisibilidade aos direitos humanos. Nesse sentido, a Declaração Universal reconhece vários direitos considerados inatos e inalienáveis aos homens, entretanto ela não tem força vinculante. Dessa forma, cabe a cada país-membro das Nações Unidas incorporar a Declaração e tomar medidas para efetivar os direitos dispostos nela, o que 
pode sofrer obstáculos em razão das diferenças culturais e socioeconômicas dos países.

É nesse contexto que a diferença jurídica entre direitos humanos e fundamentais retorna de forma evidente. Enquanto os direitos fundamentais são estabelecidos na Constituição Federal e de acordo com as particularidades do povo, os direitos humanos são estipulados de forma genérica em tratados internacionais, precisando estes de adesão pelo país para ter validade.

Os principais autores da área compreendem que o mais relevante fundamento de validade dos direitos humanos é a dignidade humana, conforme Comparato dispõe: “(...) se o direito é uma criação humana, o seu valor deriva, justamente, daquele que o criou. O que significa que esse fundamento não é outro, senão o próprio homem, considerado em sua dignidade substancial de pessoa (...)" (COMPARATO, 1997).

Desse modo, cabe-se no momento a análise da dignidade da pessoa humana. Foi com Immanuel Kant que o conceito moderno surgiu. Influenciado pelos gregos e ensinamentos cristãos, esse filósofo alemão diferenciava coisas e pessoas, compreendendo estas últimas como seres racionais e como fins em si mesmos, não podendo ser empregados como meio. Assim, a concepção de Immanuel Kant sobre a dignidade humana, a qual é amplamente utilizada nos ordenamentos jurídicos atuais, engloba os elementos "finalidade" e "autonomia da vontade".

$\mathrm{O}$ começo do século XX foi marcado por duas grandes guerras, as quais deixaram milhões de pessoas mortas, além de causar grandes movimentos de migração. Ademais, a Segunda Guerra ficou negativamente famosa em razão das atrocidades ocorridas, tais como mortes e experimentos científicos impiedosos. Nesse sentido, com o fim da Segunda Guerra Mundial, 1945, foi criada a Organização da Nações Unidas (ONU), inicialmente com 51 estados-membros. A ONU, em Assembleia realizada em 1948, proclamou a Declaração Universal dos Direitos Humanos, estabelecendo proteção universal aos direitos humanos.

Na Declaração há a previsão da dignidade da pessoa humana. Logo no preâmbulo, a dignidade é citada como inerente a todos os membros da família humana. Posteriormente, $o$ art. $1^{\circ}$, dispõe que todo ser humano é igual em dignidade e direitos. Assim, após 1948, vários outros países passaram a incluir a dignidade da pessoa humana em seus textos constitucionais. O Brasil, em sua Carta Magna de 1988, incluiu a dignidade 
da pessoa humana como um dos fundamentos do Estado Democrático de Direito.

A dignidade da pessoa humana é regularmente compreendida pela doutrina jurídica como um princípio. Desse modo, torna-se necessário entender o conceito de princípio. Os princípios são aquelas normas que precisam de ações concretizadoras por parte dos legisladores, do Judiciário ou da Administração. Assim, nos dizeres de Robert Alexy, repetidos por Gilmar Mendes: "são comandos de otimização. O grau de cumprimento do que o princípio prevê é determinado pelo seu cotejo com outros princípios e regras opostas (possibilidade jurídica) e pela consideração da realidade fática sobre a qual operará (possibilidade real)" (MENDES e BRANCO, 2015).

A doutrina é pacífica ao afirmar que a dignidade da pessoa humana como princípio tem dupla natureza funcional: ao mesmo tempo que serve como limitadora das ações dos poderes estatais e da sociedade comum, é tarefa, ou seja, um dever. Em conclusão, a dignidade da pessoa humana, estudada desde a Grécia Antiga, é um conceito subjetivo, que gera algumas controvérsias, porém norteia o ordenamento jurídico brasileiro com o objetivo de evitar abusos, principalmente do Estado em desfavor da população.

\section{A BUSCA DA FELICIDADE NO ORDENAMENTO JURÍDICO BRASILEIRO}

A felicidade pode ser classificada como um bem inato do ser humano, sendo essencial para a sua vida e tornando-se um objetivo a ser alcançado em vários momentos da sua existência. A Constituição Federal Brasileira de 1988 não prevê, explicitamente, o direito à busca da felicidade em seu texto. Entretanto, alguns doutrinadores e juristas divergem sobre essa questão: uns entendem que esse direito deriva do princípio da dignidade humana, enquanto outros defendem que, na verdade, a busca da felicidade está presente na Constituição, porém com outro nome, ou seja, bem-estar.

Um ávido defensor da ideia de que o direito à busca da felicidade decorre do princípio da dignidade da pessoa humana é o Ministro do Supremo Tribunal Federal Celso de Mello. Assim, de acordo com essa tese, sabendo que a dignidade é um atributo inerente ao ser humano e que o 
fornece igualdade de tratamento perante o Estado, seria a felicidade também uma qualidade intrínseca de todo ser humano, e não um direito. Dessa maneira, apesar de não positivada na Constituição Brasileira, a busca pela felicidade permearia todos os outros princípios e direitos.

Por outro lado, para o advogado Saul Tourinho Leal a felicidade já está inserida na Constituição Federal. Assim, segundo essa concepção, a Constituição Federal de 1988 teria interpretado felicidade como bem-estar. Este está incluído na redação de diversos dispositivos, inclusive no preâmbulo, sendo considerado o valor supremo do Estado Democrático brasileiro (LEAL, 2017).

A ideia de busca da felicidade permeia os julgados dos Tribunais de última instância do Brasil há mais de uma década. Em 2008, na importante decisão (ADI 3510) acerca da constitucionalidade da Lei de Biossegurança e o uso de células-tronco embrionárias em pesquisas científicas para fins terapêuticos no Supremo Tribunal Federal, o Ministro Celso de Mello citou o direito à felicidade como um dos fundamentos. Ademais, em decisão a favor do reconhecimento da união homoafetiva como instituição família (ADPF 132), o Ministro-relator Ayres Britto, incluiu o direito à busca da felicidade no texto.

Outra decisão em que a busca da felicidade foi amplamente utilizada como argumento é a que estabeleceu a legitimidade constitucional do reconhecimento e qualificação da união estável homoafetiva como entidade familiar ${ }^{5}$. Sob a relatoria do Ministro Celso de Mello, de 2011, esse julgado é o que melhor abarca a felicidade, determinando-a como um princípio essencial e igualando-a a outros, como os da dignidade da pessoa humana, da liberdade, da autodeterminação, da igualdade, do pluralismo, da intimidade e da não discriminação.

Entretanto, para essa utilização da busca da felicidade pelos Tribunais existem críticos, um desses é o jurista Ives Gandra Martins, conforme o exposto na seguinte notícia: "Temos um conceito coletivo de justiça, mas de felicidade é difícil (...) O direito à felicidade é invocado como se estivesse acima, sem se perceber que varia de pessoa para pessoa" (MAGRO; BASILE, 2012).

Em 2010 foi apresentado a uma das comissões do Senado Federal a chamada "PEC da felicidade". Esse Projeto de Emenda Constitucional, de autoria do então senador Cristovam Buarque, alterava o art. $6^{\circ}$ da

\footnotetext{
${ }^{5}$ RE 477554 AgR, Relator(a): Min. CELSO DE MELLO, Segunda Turma, julgado em 16/08/2011.
} 
Constituição Federal. Dessa maneira, a redação do artigo passaria a ser: "são direitos sociais, essenciais à busca da felicidade, a educação, a saúde, a alimentação, o trabalho, a moradia, o lazer, a segurança, a previdência social, a proteção à maternidade e à infância, a assistência aos desamparados, na forma desta Constituição".

Essa PEC (no 19/2010) tinha como inspiração as Constituições Japonesa e Sul-coreana, assim como o índice Felicidade Interna Bruta (FIB). Uma das justificativas para essa proposta foi a necessidade do Estado assegurar a felicidade - aqui entendida como felicidade coletiva por meio dos direitos sociais. Entretanto, essa PEC não chegou à plenário no Senado Federal e, assim, foi arquivada em dezembro de 2014.

Deste modo, a busca da felicidade, no Brasil, é compreendida de diversas formas e está presente no ordenamento jurídico brasileiro, como em jurisprudências, propostas de leis, e, para alguns, já inserida na Constituição Federal.

\section{CONSIDERAÇÕES FINAIS}

A partir da exposição acerca da felicidade, foi possível concluir que ela é abstrata e de árdua conceituação. Apesar de existirem aspectos em comum, cada indivíduo a experiencia da sua própria maneira, sendo, portanto, complexa uma aplicação prática de um direito fundamental à felicidade. Como princípio, a noção de busca da felicidade já é um pouco mais aceitável. Entretanto, o princípio da dignidade da pessoa humana tem mais respaldo teórico e é amplamente aceito no meio jurídico e político. Nesse sentido, a fim de garantir a segurança jurídica, extingue-se o princípio da busca da felicidade ou amplifica-se os estudos sobre ele.

Contudo, a autora tornou-se adepta ao entendimento semelhante àquele exposto na PEC da Felicidade: aplicar a busca da felicidade nas políticas públicas e nos direitos sociais. Essa é uma alternativa mais executável e real, além de afastar-se da questão do ativismo judicial, fenômeno polêmico em que o Poder Judiciário invade a competência de outros poderes - normalmente o Legislativo - com ações proativas, e, por muitas vezes, ameaçando o Estado Democrático de Direito.

A respeito da busca da felicidade ser derivada do princípio da dignidade humana, a presente autora discorda. A felicidade parece amparar 
a dignidade humana e vice-versa, entretanto, com a realização das investigações filosófica e científica, foi possível notar que possuem origens diferentes. Enquanto a felicidade é, geralmente, um objetivo a ser perseguido pelo indivíduo, a dignidade humana é uma característica inerente a todo ser humano, constitucionalizado para afastar as atrocidades e injustiças.

Novamente, em relação ao bem-estar ser sinônimo de felicidade, a autora opõe-se a essa noção. Bem-estar transparece a ideia de momentaneidade, enquanto felicidade, como já visto, é algo mais duradouro e comumente uma finalidade da vida humana.

Assim, aponta-se pela necessidade de mais pesquisas jurídicas acerca do tema felicidade, assunto muitas vezes desprezado por ser entendido como inútil ou espiritual. Porém, é uma das questões essenciais à vida humana, portanto, o Direito também deveria abarcá-la.

\section{REFERÊNCIAS BIBLIOGRÁFICAS}

ARISTÓTELES. Ética à Nicômaco. Tradução e notas Luciano Ferreira de Souza. São Paulo: Martin Claret, 2016.

BRASIL. [Constituição (1988)]. Constituição da República Federativa do Brasil de 1988. Brasília, DF: Presidência da República, 2019. Disponível em: <http://www.planalto.gov.br/ccivil_03/constituicao/constituicao.htm〉. Acesso em: 23 jul. 2019.

BRASIL. Proposta de Emenda à Constituição n. 19 DE 2010. Brasília, DF: Senado Federal, 2010. Disponível em: <https://legis.senado.leg.br/sdleggetter/documento?dm=4555090\&ts=1553282993979\&disposition=inline >. Acesso em: 05 ago. 2019.

BUARQUE, Cristovam. Felicidade e Política. Brasília, mai. 2012. Disponível em: $<$ http://www.senado.gov.br/senadores/senador/cristovambuarque/arquivos/PEC\%20da\%2 0Felicidade.pdf>. Acesso em: 16 fev. 2019.

CASTILHO, Ricardo. Direitos Humanos. 2. ed. São Paulo: Saraiva, 2012.

COMPARATO, Fábio Konder. Fundamento dos Direitos Humanos. Artigo apresentado ao Instituto de Estudos Avançados da USP. 1997. Disponível em: < http://www.iea.usp.br/publicacoes/textos>. Acesso em 30 jul. 2019. 
DIMOULIS, Dimitri; MARTINS, Leonardo. Teoria geral dos direitos fundamentais. 5. ed. rev., atual. ampl. São Paulo: Atlas, 2014.

ESTADOS UNIDOS DA AMÉRICA. Declaração de direitos do bom povo de Virgínia de 1776. 1776. Disponível em: <

http://www.direitoshumanos.usp.br/index.php/Documentos-anteriores-\%C3\%A0cria\%C3\%A7\%C3\%A3o-da-Sociedade-das-Na\%C3\%A7\%C3\%B5es-at\%C3\%A91919/declaracao-de-direitos-do-bom-povo-de-virginia-1776.html>. Acesso em: 15 jul. 2019.

ESTADOS UNIDOS DA AMÉRICA. Declaração de independência dos Estados Unidos da América. 1776. Disponível em:

<http://www.uel.br/pessoal/jneto/gradua/historia/recdida/declaraindepeEUAHISJNeto.pdf $>$. Acesso em: 15 jul. 2019.

FRANÇA. Constituição da Quinta República Francesa. 1958. Disponível em: $<$ https://www.conseilconstitutionnel.fr/sites/default/files/as/root/bank_mm/portugais/constitution_portugais.pdf >. Acesso em: 15 jul. 2019.

FRANÇA. Declaração dos Direitos dos Homens e dos Cidadãos de 1779. 1779.

Disponível em: <http://pfdc.pgr.mpf.mp.br/atuacao-e-conteudos-deapoio/legislacao/direitos-humanos/declar_dir_homem_cidadao.pdf $>$. Acesso em: 15 jul. 2019.

HELLIWELL, John F.; LAYARD, Richard; SACHS, Jeffrey D. World Happiness Report 2018. World Happiness Report. Disponível em: <https://worldhappiness.report/>. Acesso em: 13 jan. 2019.

JAPÃO. Constituição do Japão. 1946. Disponível em: <https://www.br.embjapan.go.jp/cultura/constituicao.html>. Acesso em 14 jul. 2019.

LEAL, Saul Tourinho. Direito à felicidade. São Paulo: Almedina, 2017.

LENOIR, Fréderic. Sobre a felicidade: uma viagem filosófica. Tradução de Vera Lucia dos Reis. 1 ed. Rio de Janeiro: Editora Objetiva, 2016.

MAGRO, Maíra; BASILE, Juliano. Direito à felicidade. Valor Econômico (on-line), São Paulo, 23 mar. 2012. Disponível em: <http://www.valor.com.br/cultura/2583386/direitofelicidade\#>. Acesso em: 16 mai. 2019.

MENDES, Gilmar Ferreira; BRANCO, Paulo Gustavo Gonet. Curso de Direito Constitucional. 1 ${ }^{\text {a }}$. ed. rev. e atual. São Paulo: Saraiva, 2015.

MILL, John Stuart. Utilitarismo. Tradução F. J. Azevedo Gonçalves. Lisboa: Gadiva, 2005 . 
ONU. Declaração Universal dos Direitos Humanos. 1948. Disponível em: <https://nacoesunidas.org/wp-content/uploads/2018/10/DUDH.pdf>. Acesso em: 16 jul. 2019.

REINO DO BUTÃO. Constituição do Reino do Butão. 2008. Disponível em: <https://web.archive.org/web/20120928030946/http:/www.constitution.bt/html/constitutio n/constitution.htm>. Acesso em: 15 jul. 2019.

REPÚBLICA DA COREIA. Constituição Federal da República da Coreia. Disponível em: 〈http://www.idcc.org.br/constituicoes/constituicao-estrageira〉. Acesso em: 30 jul. 2019 .

SEABRA, P., Sarreira, et. al. A felicidade em pessoas com doença mental: Uma revisão integrativa da literatura. Revista Portuguesa de Enfermagem de Saúde Mental, n. 19, jun. 2018, pg. 45-53. Disponível em: <doi: 10.19131/rpesm.0201> Acesso em: 22 fev. 2019.

SOUZA, Maicon Melito de. A evolução histórica das fontes basilares dos direitos fundamentais. Revista eletrônica da Faculdade de Direito de Franca, Franca, v. 12, n. 1, jul. 2017. Disponível em: < http://revista.direitofranca.br/index.php/refdf/article/view/341/pdf>. Acesso em: 17 mai. 2019.

WARBURTON, Nigel. Uma breve história da filosofia. Tradução Rogério Bettoni. Porto Alegre, RS: L\&PM, 2012. 